\title{
Penegakan Hukum Pemalsuan Surat Disebabkan Penyerobotan Hak Atas Tanah
}

\author{
Fatika Sari1, Yeni Widowaty $^{2}$, Leli Joko Suryono ${ }^{3}$ \\ 1,2,3 Fakultas Hukum, Universitas Muhammadiyah Yogyakarta \\ Email : ${ }^{1}$ fatika.sari.2016@law.umy.ac.id \\ 2 yeniwidowaty@umy.ac.id \\ 3 lelijoko@umy.ac.id
}

\begin{tabular}{|c|c|}
\hline Info Art & \\
\hline Riwayat: & \\
\hline Diajukan & : 27 Oktober 2020 \\
\hline Direview & : 1 November 2020 \\
\hline Direvisi & : 5 November 2020 \\
\hline Diterima & : 9 November 2020 \\
\hline $\begin{array}{l}\text { Kata Kun } \\
\text { hak atas } t \\
\text { surat; pen } \\
\text { penyerobc }\end{array}$ & $\begin{array}{l}\text { i: } \\
\text { nah; pemalsuan } \\
\text { gakan hukum; } \\
\text { an; pemalsuan surat }\end{array}$ \\
\hline DOI: & $v 1 i 3.11$ \\
\hline
\end{tabular}

\begin{abstract}
Abstrak
Hak penguasaan atas tanah dapat dibuktikan oleh sertipikat yang berlaku sebagai alat bukti kuat mengenai data fisik dan yuridis yang dimuat didalamnya. Bukti kepemilikan hak atas tanah ini sering menimbulkan sengketa yang menimbulkan perkara penyerobotan. Penyerobotan terjadi karena tindak pemalsuan surat. Pemalsuan surat sendiri merupakan salah satu tindak pidana yang di atur dalam Pasal 263 ayat (2) KUHP. Tulisan ini akan menjelaskan lebih lanjut tentang penegakan hukum pidana pemalsuan surat hak atas tanah yang disebabkan karena penyerobotan hak atas tanah. Penelitian ini menggunakan metode penelitian yuridis empiris dengan pendekatan kualitatif dengan sumber data primer dan sekunder. Hasil penelitian di temukan bahwa penegakan hukum pidana yang penulis analisis menggunakan Pasal 263 ayat (1) dan ayat (2) yang mencantumkan hukuman atau saksi paling lama enam tahun penjara. Adapun sanksi pidana penjara selama sepuluh bulan dijatuhkan terhadap terdakwa Muhardin Als Muhar sesuai dengan putusan nomor 374/Pid.B/2019/PN. Bgl. Sedangkan terdakwa Abdul Sanapudin di bebaskandari semua dakwaan sesuai dengan Putusan Nomor 424/Pid.B/2018/PN.Bgl.
\end{abstract}

\section{Pendahuluan}

Penguasaan tanah dibagi menjadi tiga kategori berdasarkan siapa yang menguasai tanah tersebut. Penguasaan pertama dilakukan oleh negara, penguasaan kedua dilakukan oleh masyarakat hukum adat dan ketiga dilakukan oleh individu atau badan hukum. Penguasaan tanah oleh individu atau badan hukum berkaitan dengan pemberian hak atau kewenangan kepada orang atau badan untuk memanfaatkan dan menggunakan tanah tersebut untuk kepentingannya. ${ }^{1}$

Hak penguasaan atas tanah dibuktikan dengan sertipikat yang berlaku ditemukan perkara hak atas tanah, seperti di Provinsi Bengkulu. Hasil rekap Badan Pertanahan Nasional tanah 2019 terdapat 42 (empat puluh dua) kasus pertanahan dengan 12 (dua belas) kasus diselesaikan secara mediasi dan 13 (tiga belas) kasus diselesaikan melalui pengadilan. ${ }^{2}$

Salah satu perkara hak atas penguasaan tanah disebut penyerobotan hak atas tanah. Penyerobotan adalah perbuatan mengambil harta dan/atau hak dengan sewenang-wenang tanpa memiliki alasan kuat, dan tidak menghiraukan hukum dan aturan. ${ }^{3}$ Penyerobotan dalam hukum perdata merupakan jenis perbuatan melawan hukum dengan unsur kesengajaan. ${ }^{4}$

\footnotetext{
${ }^{1}$ Arba. (2015). Hukum Agraria Indonesia. Jakarta: Sinar Grafika. hlm. 82

${ }^{2}$ Badan Pertanahan Nasional. Melalui Referensi dari Internet. Diakses pada 25 Desember 2019. http://www.atrbpn.go.id/Berita/Data-Pertanahan/Kasus-Pertanahan/provinsi, (21.28)

${ }^{3}$ Robert Weku. (2013). "Kajian Terhadap Kasus Penyerobotan Tanah Ditinjau Dari Aspek Hukum Pidana dan Hukum Perdata." Lex Privatum 1, (2).hlm. 166.

${ }^{4}$ Muir Fuady. (2017). "Perbuatan Melawan Hukum Pedakatan Kontemporer”. Bandung: Citra Aditya Bakti. hlm. 55.
} 
Hak atas tanah yang dimiliki secara terus-menerus, berkesinambungan dan teratur, di data dengan pengumpulan, pengolahan, pembukuan, dan penyajian serta pemeliharaan data fisik dan yuridis dalam bentuk peta dan daftar mengenai bidang-bidang tanah dan satuan-satuan rumah susun kegiatan ini disebut pendaftaran tanah. ${ }^{5}$ Pendaftaran hak atas tanah dilakukan untuk memberi kepastian hukum dan perlindungan hukum kepada pemegang hak atas tanah; menyediakan informasi kepada pihak-pihak yang berkepentingan; menyelenggarakan tertib administrasi pertanahan. ${ }^{6}$

Kegiatan tersebut akan memberikan akibat hukum berupa sertipikat sebagai tanda hak atas tanah. Sertipikat akan memberi kepastian hukum yang terbagi menjadi 3 (tiga), yaitu: kepastian hukum status hak atas tanah yang didaftarkan, kepastian hukum subjek hak atas tanah, kepastian hukum objek hak atas tanah. ${ }^{7}$

Bukti kepemilikan hak atas tanah ini sering menimbulkan sengketa yang menimbulkan perkara penyerobotan. Penyerobotan terjadi karena tindak pemalsuan surat. Tindak pemalsuan surat adalah pemalsuan surat-surat berharga dan pemalsuan mata uang, dan ditambah dengan sejumlah tindak pidana yang sebenarnya tidak dapat dipandang sebagai pemalsuan-pemalsuan, sehingga dalam doktrin disebut quasti falsum atau pemalsuan yag bersifat semu. ${ }^{8}$

Membuat surat palsu ialah membuat seluruh surat yang seluruh atau sebagian isinya palsu. Palsu artinya tidak benar atau bertentangan dengan yang sebenarnya. Membuat surat palsu dapat berupa halhal berikut:

1. Membuat sebuah surat yang sebagian atau seluruh isi surat tidak sesuai atau bertentang dengan kebenaran. Membuat surat palsu yang demikian disebut dengan pemalsuan intelektual (intelectuele valschheid).

2. Membuat sebuah surat yang seolah-olah surat itu berasal dari orang lain selain si pembuat surat. Membuat surat palsu yang demikian ini disebut dengan pemalsuan materiil (materiele valschheid). Palsunya surat atau tidak benarnya surat terletak pada asalnya atau si pembuat.

Contoh perkara hak atas tanah antara individu dan individu, seperti sengketa antara pemilik tanah yang mendapat hak atas tanah melalui jual beli dengan bukti sertipikat hak atas tanah. Kemudian muncul pihak dua yang juga mengaku sebagai pemilik hak atas tanah dengan bukti surat penyerahan tanah, surat keterangan penguasaan hak atas tanah yang didapat dari jual beli dengan pihak tiga. Pihak tiga tidak memiliki hubungan dengan hak atas tanah dari lahan tersebut, maka sengketa tanah dilaporkan ke pengadilan dan diproses secara pidana setelah jelas siapa pemilik hak atas tanah berdasarkan putusan pengadilan secara perdata.

Berdasarkan putusan pengadilan pidana pihak tiga telah melakukan pemalsuan surat sesuai dengan Pasal 263 ayat (2) KUHP yaitu "Diancam dengan pidana yang sama barang siapa dengan sengaja memakai surat yang isinya tidak benar atau dipalsukan, seolah-olah benar dan tidak dipalsu, jika pemakaian dapat menimbulkan kerugian", karena surat yang dipalsukan oleh pihak tiga mengakibat kerugian kepada pemilik hak atas tanah dan pihak dua.

Rumusan tindak pemalsuan surat didukung dengan penegakan hukum yang sesuai agar terwujud ide-ide dan konsep-konsep yang nota bene nya abstrak. ${ }^{9}$ penegakan hukum memiliki pengertian yang bersifat makro dan mikro. Bersifat makro jika dibatasi dalam proses pemeriksaan di pengadilan termasuk penyelidikan, penyidikan, penuntutan hingga pelaksanaan putusan pidana yang memiliki hukum tetap.

\footnotetext{
${ }_{6}^{5}$ Adrian Sutedi. (2014). Sertifikat Hak atas tanah. Jakarta: Sinar Grafika. hlm. 114

${ }^{6}$ Ibid., hlm. 46

${ }^{7}$ Bronto Susanto. (2014). "Kepastian Hukum Sertifikat Hak Atas Tanah Berdasarkan Peraturan Pemerintah Nomor 24 Tahun 1997." DiH: Jurnal Ilmu Hukum 10, (20). hlm. 80

${ }^{8}$ Nanda Putri Mardi Utami. (2017). "Penegakan Hukum Terhadap Tindak Pidana Pemalsuan Surat Yang Dilakukan Oleh Anggota TNI Dalam Wilayah Hukum Pengadilan Militer II-11 Yogyakarta”. (Skripsi tidak diterbitkan). Fakultas Hukum Universitas Muhammadiyah Yogyakarta. hlm. 14

${ }^{9}$ Satjipto Raharjo. (2009). Penegakan Hukum Suatu Tinjauan Sosiologis. Yogyakarta: Penerbit Genta Publishing. hlm, 12.
} 
Penegakan hukum bersifat makro mencakup seluruh aspek kehidupan masyarakat berbangsa dan bernegara. ${ }^{10}$

\section{Rumusan Masalah}

Bagaimana penegakan hukum pidana pemalsuan surat yang di sebabkan karena penyerobotan hak atas tanah?

\section{Metode Penelitian}

Penulis menggunakan jenis penelitian yuridis empiris, yakni penelitian yang dilakukan dengan cara mengamati, memperhatikan, dan meninjau secara langsung pola perilaku masyarakat yang didukung dengan studi kepustakaan, dimana perilaku masyarakat ini timbul karena adanya interaksi dengan sistem norma yang ada. ${ }^{11}$ Penulis menggunakan dan mengumpulkan data primer yang diperoleh dari wawancara terhadap narasumber Kepala Sub Bagian Tata Usaha Ibu Euis Yeni Syarifah, S.H., M.M. (Badan Pertanahan Nasional Kantor Pertanahan Nasional Kota Bengkulu), Ibu Dian Febianti, S.H (Kejaksaan Negeri Kota Bengkulu Ajun Jaksa (III/b)), dan Bapak Hascaryo, S.H., M.H. (Hakim Pengadilan Negeri Kota Bengkulu) dan data sekunder yang diperoleh dari studi kepustakaan. Data tersebut akan di analisis menggunakan metode deduktif dengan pendekatan kualitatif. ${ }^{12}$

\section{Hasil dan Pembahasan}

Hak atas tanah ialah hak yang memberi wewenang kepada pemilik hak untuk mengambil atau menggunakan manfaat dari tanah yang dihakinya. ${ }^{13}$ Hak atas tanah menjadi permasalahan di masyarakat yang terus berkembang karena ingin memanfaatkan tanah tersebut. Penyerobotan hak atas tanah yang didasari oleh kepemilikan surat dapat diselesaikan dengan cara mengajukan gugatan ke pengadilan negeri setempat. Gugatan berbentuk gugatan perbuatan melawan hukum guna mencari kebenaran atas pemilik sesungguhnya terhadap tanah tersebut. Adapun jumlah perkara yang diselesaikan secara perdata ialah seperti tabel berikut :

Daftar Perkara Perdata dan Pidana 2018-2019

1. PN Bengkulu 51/Pdt.G/2018/PN.Bgl: Sengketa Pemilikan Hak Atas Tanah. penggugat : Chairul Nasikin tergugat I : Susilawati tergugat II : pemerintah RI Cq. kementrian pendidikan dan kebudayaan provinsi Bengkulu turut tergugat : kantor pertanahan kota

2. PN Bengkulu 65/Pdt.G/2018/PN.Bgl: gugatan terhadap sertifikat hak milik tanah nomor : 00657 An. Zulkardi Bin Alm wari (turut tergugat II) SHM Nomor : 05311 An. Buiston Husin Haur Bin Alm. Asmawi (Tergugat VIII) SHM Nomor : 00660 An. Sukmawati (Tergugat XIII) yang diklaim oleh Hj. Nursiah Binti Alm. Mukmin dkk adalah tanah miliknya. Penggugat : Hj. Nursiah Binti Alm Tergugat : Tarisno Bin Am. Yusuf dkk ( 11 orang ) Turut Tergugat : Edison, dkk (7 orang) Tergugat XIII : Kantor Pertanahan kota Bengkulu.

3. PN. Bengkulu 2/Pdt.G/2019/PN.Bgl: Penggugat : adil sitepu tergugat : Rosinta Hutasoit dkk. Turut Tergugat : kantor pertanahan Kota Bengkulu. Gugatan terhadap sertifikat hak milik nomor : 05396 An. rosinta hutasoit yang di klaim oleh adil sitepu adalah tanah miliknya.

4. PN. Bengkulu 6/Pdt.G/2019/ PN.Bgl: Penggugat : Syamsi, Tergugat : Liang Purnomo. Turut Tergugat I : PT. Bright Morning Sight. Turut Tergugat II : Kantor Pertanahan Kota Bengkulu. Gugatan terhadap

\footnotetext{
${ }^{10}$ Slamet Tri Wahyudi. (2012). "Problematika Penerapan Pidana Mati Dalam Konteks Penegakan Hukum Di Indonesia." Jurnal Hukum dan Peradilan 1, (2). ISSN : 2303-3274.

${ }^{11}$ Mukti Fajar ND \& Yulianto Achmad. (2015). Dualisme Penelitian Hukum Normatif \& Empiris. Yogyakarta:

Penerbit Pustaka Pelajar. hlm. 51.

${ }^{12}$ Ibid, hlm. 192.

${ }^{13}$ Urip. (2010). Pendaftaran dan Peralihan Hak Atas Tanah. Jakarta: Prenada Media. hlm. 49
} 
sertifikat hak guna bangunan nomor : 08650 An. PT. Bright Morning Sight seluas 51.040 M2 yang di klaim oleh Syamsi adalah tanah miliknya.

5. PN. Bengkulu 13/Pdt.G/2019/PN.Bgl: penggugat : Adil Sitepu tergugat : Rosinta Hutasoit dkk Bengkulu. Gugatan terhadap sertifikat hak milik nomor : 05396 An. rosinta hutasoit yang di klaim oleh adil sitepu adalah tanah miliknya

Sumber: Laporan penanganan sengketa konflik dan perkara pertanahan pada kantor pertanahan Kota Bengkulu

Penyerobotan hak atas tanah yang terjadi karena pihak penyerobot merasa sebagai pemilik hak atas tanah, setelah melalui persidangan di pengadilan dengan jalur perdata ternyata menyerobot karena memiliki surat kepemilikan palsu. Pemalsuan surat kepemilikan hak tanah tersebut dipertanggungjawabkan di pengadilan dengan ancaman pidana sesuai dengan tindakan. Berikut adalah daftar perkara pidana tentang pemalsuan surat tanah yang mengakibatkan orang menyerobot tanah pihak lain :

1. PN. Bengkulu 424/Pid.B/ 2018/ PN. Bgl: Terpidana : Abdul Sanapudin bin Masud. Pemalsuan surat tanah yang mengakibat kan kerugian pada orang lain.

2. PN. Bengkulu 563/Pid.B/ 2018/ PN. Bgl: Terpidana : Iskandar als Is Bin Bachtiar. Pemalsuan surat tanah yang mengakibat kan kerugian pada orang lain.

3. PN. Bengkulu 374/Pid.B/2019/PN Bgl: Terpidana : Mahardin als Muhar Bin Mat Tain. Pemalsuan surat tanah yang mengakibat kan kerugian pada orang lain

(Sumber : Putusan Makamah Agung)

Penegakan hukum untuk menyelesaikan perkara ini berdasarkan wawancara dengan hakim Pengadilan Negeri Bengkulu adalah melaporkan ke kepolisian untuk dilakukan penyidikan dan penyelidikan. Penyidikan dan penyelidikan yang telah cukup di ajukan ke penuntut umum untuk membuat dakwaan. Dakwaan menjadi pedoman untuk mencari kebenaran sebenar-benarnya. Hakim akan menilai pembuktian atas dakwaan penuntut umum sesuai dengan Pasal 184 KUHAP tentang alat bukti yaitu: keterangan saksi; keterangan ahli; surat; petunjuk; dan keterangan terdakwa. ${ }^{14}$

Penegakan hukum pidana yang penulis analisis menggunakan Pasal 263 ayat (1) dan ayat (2) yang mencantumkan hukuman atau saksi paling lama enam tahun penjara. Adapun analisa berdasar tabel di atas akan dilakukan terhadap putusan nomor 424/Pid.B/2018/PN.Bgl dan 374/Pid.B/2019/PN. Bgl, sebagai berikut :

Dalam putusan 347/Pid.B/2019/PN.Bgl tindak pidana yang terbukti dilakukan oleh terpidana adalah menggunakan surat palsu sesuai Pasal 263 ayat (2) "diancam pidana penjara paling lama enam tahun barang siapa dengan sengaja memakai surat yang isinya tidak benar atau dipalsu, seolah-olah benar dan tidak dipalsu, jika pemakaian surat dapat menimbulkan kerugian", terpidana menggunakan surat yang dipalsukan untuk menjual hak atas tanah sebidang tanah kepada orang lain dengan perbuatan tersebut terpidana mengakibatkan orang yang membeli tanah dari dia mempercayai jika dia memiliki hak atas tanah tersebut. Namun hak atas tanah tersebut telah dimiliki oleh pihak lain, dengan adanya kepercayaan kepemilikan tersebut membuat pihak yang membeli tanah dari terpidana berusaha mengambil/menyerobotan tanah tersebut dari pemilik sahnya. Penegakan hukum pidana pemalsuan surat hak atas tanah dikenakan sanksi pidana penjara selama 10 (sepuluh) bulan.

Dalam putusan 424/Pid.B/2019/PN.Bgl tindak pidana yang didakwakan adalah "membuat surat palsu" subsidair "menggunakan surat palsu". Namun, kedua dakwaan tidak terbukti secara sah dan meyakinkan di proses pembuktian sehingga majelis hakim memutuskan untuk membebaskan terdakwa dan melakukan rehabilitasi kepadanya. Berdasarkan putusan tersebut penulis menyimpulkan bahwa terdakwa tidak mengetahui jika ia telah menguasai hak atas tanah tersebut dengan dasar palsu, dan dengan keyakinan yang subyektif mempercayai bahwa terdakwa adalah pemilik sah atas tanah yang dikelolanya.

14 Wawancara Hakim Pengadilan 


\section{Simpulan}

Penegakan hukum pidana pemalsuan surat dilakukan dengan melakukan laporan ke kepolisian kemudian kejaksaan akan menuntut orang yang telah melakukan penyerobotan dipengadilan sesuai dengan KUHAP. Penegakan hukum pidana yang penulis analisis menggunakan Pasal 263 ayat (1) dan ayat (2) yang mencantumkan hukuman atau saksi paling lama enam tahun penjara. Adapun sanksi pidana penjara selama sepuluh bulan dijatuhkan terhadap terdakwa Muhardin Als Muhar sesuai dengan putusan nomor 374/Pid.B/2019/PN. Bgl. Sedangkan terdakwa Abdul Sanapudin di bebaskandari semua dakwaan sesuai dengan Putusan Nomor 424/Pid.B/2018/PN.Bgl

\section{Daftar Pustaka}

\section{Buku}

Adami Chazawi. (2005). Kejahatan Mengenai Pemalsuan. PT Raja Grafindo Persada: Jakarta.

Adrian Sutedi. (2014). Sertifikat Hak Atas Tanah. Jakarta: Sinar Grafika.

Arba. (2015). Hukum Agraria Indonesia. Jakarta: Sinar Grafika.

Erna Sri Wibawanti, R. Mujianto. (2013). Hak Atas Tanah dan Peralihannya. Yogyakarta: Liberty Yogyakata.

Mukti Fajar Nd, Yulianto Ahmad. (2015). Dualisme Penelitian Hukum. Yogyakarta: Fakultas Hukum Universitas Muhammadiyah Yogyakarta.

Munir Fuady. (2017). "Perbuatan Melawan Hukum Pendekatan Kontemporer". Bandung: Citra Aditya Bakti.

Satjipto Raharjo. (2009). Penegakan Hukum Suatu Tinjauan Sosiologis. Yogyakarta: Penerbit Genta Publishing.

Soejorno Soekanto. (2002). Faktor-faktor yang Mempengaruhi Penegakan Hukum. Jakarta: Raja Grafindo Persada.

Supriadi. (2018). Hukum Agraria. Jakarta: Sinar Grafika.

Urip Santoso. (2010). Pendaftaran dan Peralihan Hak Atas Tanah. Jakarta: Prenada Media.

Jurnal

Bronto Susanto. (2014). "Kepastian Hukum Sertifikat Hak Atas Tanah Berdasarkan Peraturan Pemerintah Nomor 24 Tahun 1997." DiH: Jurnal Ilmu Hukum 10, (20).

Robert Weku. (2013). "Kajian Terhadap Kasus Penyerobotan Tanah Ditinjau Dari Aspek Hukum Pidana dan Hukum Perdata." Lex Privatum 1, (2).

Slamet Tri Wahyudi. (2012). "Problematika Penerapan Pidana Mati Dalam Konteks Penegakan Hukum Di Indonesia." Jurnal Hukum dan Peradilan 1, (2).

\section{Skripsi}

Muhammad Yusril Ramadhan. (2017). "Pemidanaan Terhadap Pelaku Tindak Pidana Pemalsuan dan Pengedaran Uang Palsu". (Skripsi tidak diterbitkan). Fakultas Hukum Universitas Muhammadiyah Yogyakarta.

Nabilla N.H.. (2019). "Perbuatan Melawan Hukum sebagai Dasar Gugatan Sengketa Tanah (Studi kasus Putusan Nomor 53/Pdt. G/ 2016/PN. Kln)". (Skripsi tidak diterbitkan). Fakultas Hukum Universitas Muhammadiyah Yogyakarta. 


\section{Website}

Badan Pertanahan Nasional. Melalui Referensi dari Internet. Diakses 25 Desember 2019, https://www.atrbpn.go.id/Berita/Data-Pertanahan/Kasus-Pertanahan/Propinsi.

\section{Wawancara}

Wawancara Badan Pertanahan Nasional Kota Bengkulu

Wawancara kejaksaan Negeri Kota Bengkulu

Wawancara Hakim Pengadilan Negeri Bengkulu 